Liver, Pancreas and Biliary Tract

\title{
Current practice of hepatitis C treatment in Southern Italy
}

\author{
Tommaso Stroffolini $^{\mathrm{a}, *}$, Aldo Spadaro $^{\mathrm{b}}$, Vincenzo Guadagnino ${ }^{\mathrm{c}}$, Stefano Cosentino ${ }^{\mathrm{d}}$, \\ Filippo Fatuzzo ${ }^{\mathrm{e}}$, Antonio Galdieri ${ }^{\mathrm{f}}$, Bruno Cacopardo ${ }^{\mathrm{g}}$, Ignazio Scalisi ${ }^{\mathrm{h}}$, Mauro Sapienza ${ }^{\mathrm{i}}$, \\ Maurizio Russello ${ }^{\mathrm{j}}$, Gaetano Scifo ${ }^{\mathrm{k}}$, Pierluigi Frugiuele ${ }^{\mathrm{l}}$, Giuseppe Foti ${ }^{\mathrm{m}}$, Piero Luigi Almasio ${ }^{\mathrm{n}}$, \\ The Gr.E.Ca.S. Hospitals' Collaborating Group ${ }^{1}$
}

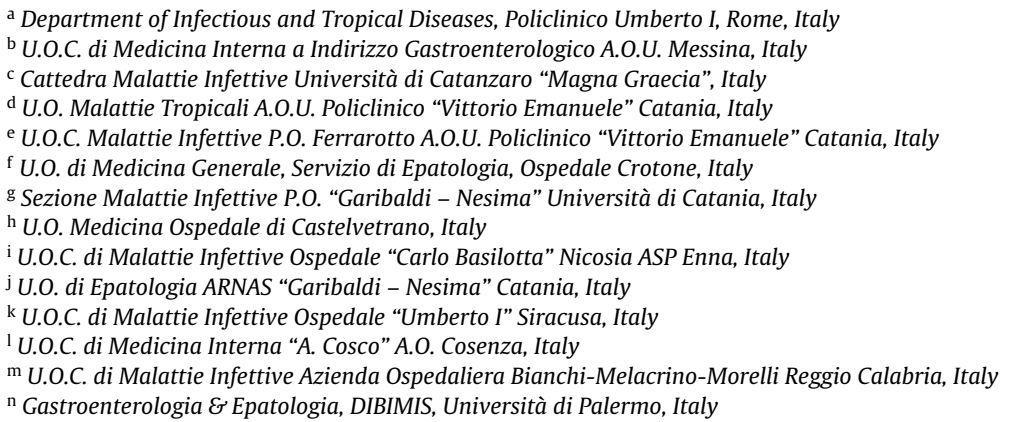

\section{A R T I C L E I N F O}

\section{Article history:}

Received 12 January 2010

Accepted 24 March 2010

\section{Keywords:}

Antiviral therapy

Chronic hepatitis

$\mathrm{HCV}$

\begin{abstract}
A B S T R A C T
Background: Only a small proportion of subjects referring to hospitals for hepatitis C virus (HCV) positivity receives antiviral therapy.

Aim: To evaluate the rate of antiviral treatment and the causes for no treatment in HCV-RNA positive subjects seen in hospital settings.

Patients and methods: A prospective study enrolling over a 6-month period (February-July 2009) all consecutive anti-HCV positive subjects initially referred (naïve patients) to 12 liver units in Southern Italy for HCV treatment.

Results: Out of 608 subjects evaluated, 74 (12.2\%) had no detectable HCV-RNA in the serum and thus were excluded. Of the remaining 534 HCV-RNA positive subjects, 357 (66.9\%) were not treated for the following reasons: $49.9 \%$ were older than 65 years of age ( $75 \%$ of them $>70$ years), $14.3 \%$ had normal liver enzymes, $13.2 \%$ had compensated/decompensated cirrhosis, $10.4 \%$ refused treatment, $9.8 \%$ had ongoing substance or alcohol abuse. Multivariate analysis showed that females (O.R. 2.27; C.I. 95\% 1.05-4.90) and subjects with low educational level (O.R. 4.38; C.I. 95\% 1.27-15.11) were more likely to decline therapy. Conclusions: The majority of patients with HCV infection does not receive antiviral treatment. The effectiveness of the current standard therapy for HCV infection is low despite its good efficacy.
\end{abstract}

(c) 2010 Editrice Gastroenterologica Italiana S.r.l. Published by Elsevier Ltd. All rights reserved.

\section{Introduction}

The current standard treatment for chronic hepatitis $C$ virus (HCV) infection, i.e. pegylated interferon (PEG-IFN) plus ribavirin, can achieve viral clearance in the majority of treated patients. The

\footnotetext{
* Corresponding author.

E-mail address: tommaso.stroffolini@iss.it (T. Stroffolini).

1 Authors from the collaborating group: C. Morace, Messina; B. Caroleo, Catanzaro; L. Mariani, Catania; A. Montineri, Catania; F. Felice, Crotone; F. Benanti, Catania; G. Gioia, Castelvetrano; P. Benenati, Enna; A. Bellia, Catania; M. Di Stefano, Siracusa; T. De Bartolo, Cosenza; S. De Lorenzo, Reggio Calabria.
}

proportion of subjects who obtain a sustained virological response (i.e. serum HCV-RNA negativity 6 months after the end of scheduled therapy) may be $>50 \%$ in those infected by HCV genotype 1 , and more than $80 \%$ in those infected by genotype 2 or 3 [1].

Unfortunately, only a small proportion of subjects referred to hospitals for HCV positivity receives treatment. In the U.S.A., from $28 \%$ [2] to $35 \%$ [3] of HCV-RNA positive subjects are treated. In Italy, a study conducted in a single referral centre showed that only $26 \%$ of evaluated $\mathrm{HCV}$ positive subjects were treated [4]. In a recent survey evaluating the effectiveness of antiviral treatment in the general anti-HCV positive population, only 8 (9.5\%) out of $84 \mathrm{HCV}$ RNA positive subjects detected by a random screening from the 
Table 1

Comparison of baseline features according to antiviral treatment in 534 serum HCV-RNA positive patients.

\begin{tabular}{|c|c|c|c|c|}
\hline & All patients $(n=534)$ & Treated patients ${ }^{\mathrm{a}}(n=177)(33.1 \%)$ & Untreated patients $^{\mathrm{a}}(n=357)(66.9 \%)$ & $p$-Value \\
\hline Age, years (mean \pm S.D.) & $60.7 \pm 14.4$ & $51.7 \pm 12.2$ & $65.1 \pm 12.3$ & $<0.001$ \\
\hline \multicolumn{5}{|l|}{ Gender } \\
\hline Male & $288(53.9 \%)$ & $100(56.5 \%)$ & $188(52.7 \%)$ & \multirow[t]{2}{*}{0.3} \\
\hline Female & $246(46.1 \%)$ & $77(43.5 \%)$ & $169(47.3 \%)$ & \\
\hline B.M.I., $\mathrm{kg} / \mathrm{m}^{2}$ (mean \pm S.D.) & $26.1 \pm 3.7$ & $25.8 \pm 3.6$ & $26.2 \pm 3.8$ & 0.2 \\
\hline ALT, IU $/ \mathrm{ml}$ (mean \pm S.D.) & $84 \pm 75$ & $104 \pm 90$ & $74 \pm 65$ & $<0.001$ \\
\hline \multicolumn{5}{|l|}{ Years of schooling ${ }^{\mathrm{a}}$} \\
\hline$<6$ & $140(28.6 \%)$ & $28(17.7 \%)$ & $112(33.8 \%)$ & \multirow[t]{3}{*}{$<0.001$} \\
\hline $6-13$ & $249(50.9 \%)$ & $82(51.9 \%)$ & $167(50.5 \%)$ & \\
\hline$>13$ & $100(20.4 \%)$ & $48(30.4 \%)$ & $52(15.7 \%)$ & \\
\hline \multicolumn{5}{|l|}{ HCV genotype } \\
\hline $1 \mathrm{a} / 1 \mathrm{~b}$ & $251(65.2 \%)$ & $98(60.9 \%)$ & $153(68.3 \%)$ & \multirow[t]{5}{*}{0.014} \\
\hline $2 a / 2 c$ & $99(25.7 \%)$ & $41(25.5 \%)$ & $58(25.9 \%)$ & \\
\hline $3 a$ & $26(6.8 \%)$ & $14(8.6 \%)$ & $12(5.4 \%)$ & \\
\hline 4 & $9(2.3 \%)$ & $8(5.0 \%)$ & $1(0.4 \%)$ & \\
\hline Missing & $149(27.9 \%)$ & & & \\
\hline \multicolumn{5}{|l|}{ Diagnosis } \\
\hline PNALT carrier & $64(12.0 \%)$ & $4(2.3 \%)$ & $60(16.8 \%)$ & \multirow[t]{3}{*}{$<0.001$} \\
\hline Chronic hepatitis & $389(72.8 \%)$ & $161(91.0 \%)$ & $228(63.9 \%)$ & \\
\hline Cirrhosis & $84(15.2 \%)$ & $12(6.7 \%)$ & $69(19.3 \%)$ & \\
\hline \multicolumn{5}{|l|}{ Liver biopsy } \\
\hline Yes & $130(24.3 \%)$ & $85(48.0 \%)$ & $45(12.6 \%)$ & \multirow[t]{2}{*}{$<0.001$} \\
\hline No & $404(75.7 \%)$ & $92(52.0 \%)$ & $312(87.4 \%)$ & \\
\hline \multicolumn{5}{|l|}{ Referral pattern ${ }^{\mathrm{a}}$} \\
\hline Self-referral & $62(12.0 \%)$ & $21(12.4 \%)$ & $41(11.7 \%)$ & \multirow[t]{3}{*}{0.5} \\
\hline General practitioner & $293(56.6 \%)$ & $101(59.8 \%)$ & $192(55.0 \%)$ & \\
\hline Other & $163(31.4 \%)$ & $47(27.8 \%)$ & $116(33.3 \%)$ & \\
\hline
\end{tabular}

a Some data are missing. PNALT: persistently normal alanine aminotransferase.

general population received treatment [5]. However, because the two Italian studies were both performed in a single Hepatology unit, results may have been affected by a potential bias due to centre effect.

We performed a prospective study to assess the treatment rate and the causes for non-treatment in HCV-RNA positive subjects referred to various liver units in Southern Italy.

\section{Methods}

\subsection{Study population}

During a 6-month period (February-July 2009) all consecutive anti-HCV positive subjects initially referred (naïve patients) to 12 liver units located in two Southern Italian Regions (Calabria and Sicily) were recruited. Patients were eligible for the study if they were older than 18 years of age, had a positive anti-HCV test by ELISA and were under consideration for HCV treatment with PEGIFN plus ribavirin. Patients were excluded from the study if they had undetectable HCV-RNA by PCR.

\subsection{Study design}

At the time of enrolment, all patients received comprehensive counselling by a treating physician, including natural history and prognosis of chronic HCV infection and treatment options. The treating clinician at each centre was a gastroenterologist, hepatologist, or infectious diseases specialist who was experienced in the management of patients with chronic HCV infection. Patients were evaluated for HCV therapies by the clinician using standardized criteria based on current international treatment guidelines. Demographic information and results of laboratory testing were recorded on standardized data collection sheets.

\subsection{Laboratory assay}

The presence of HCV-RNA was determined using PCR. The lower limit of detection was $15 \mathrm{IU} / \mathrm{ml}$. HCV genotyping was performed using the INNO-LIPA HCV II assay (Innogenetics, Gent, Belgium). The virological assays were performed in the laboratories of the different hospitals participating to the study.

\subsection{Statistical analysis}

Differences in proportions and means were evaluated by a chisquared test or a Student's $t$-test, respectively. A $p$ value $<0.05$ was considered to be significant. Univariate analysis was used to identify the crude Odds Ratios (O.R.) for the association of different variables with declining therapy in subjects eligible for treatment. Subsequently, multivariate regression analysis was performed to identify the independent predictors and their 95\% Confidence Intervals (C.I.) of declining therapy.

\section{Results}

Of the 608 subjects who were evaluated after testing positive for HCV antibody, 74 (12.2\%) had no detectable HCV-RNA and thus were excluded from the survey. Of the remaining $534 \mathrm{HCV}$-infected subjects, 357 (66.9\%) were not treated. Compared to the 177 subjects receiving treatment, these 357 untreated patients were more likely older (mean age 65.1 vs. 51.7 years; $p<0.01$ ), with lower mean ALT values ( 74 vs. $104 \mathrm{IU} / \mathrm{ml} ; p<0.01$ ), with lowest number of years of schooling ( $33.8 \%$ vs. $17.7 \% ; p<0.01$ ) (Table 1 ).

Non-mutually exclusive causes of non-treatment are reported in Table 2. Nearly half of cases (49.3\%) was not treated because of age $>65$ years ( $75 \%$ were older than 70 years of age). Normal ALT and cirrhosis represented $14.3 \%$ and $13.2 \%$, respectively of untreated cases. The proportion of refusals was $10.4 \%$. 
Table 2

Reasons for withholding antiviral treatment in 357 anti-HCV positive patients. Note: more than one item in the same patient.

\begin{tabular}{lcc}
\hline & Number of subjects & $\%$ \\
\hline Age $>$ 65 years & $176^{\mathrm{a}}$ & 49.3 \\
Normal ALT & 51 & 14.3 \\
Compensated/decompensated cirrhosis & 47 & 13.2 \\
Psychiatric disease & 37 & 10.4 \\
Patient's refusal & 37 & 10.4 \\
Drug addiction/alcohol abuse & 35 & 9.8 \\
Decompensated diabetes & 26 & 7.3 \\
Heart disease & 18 & 5.0 \\
Mild necro-inflammation & 17 & 4.8 \\
Thyroiditis & 17 & 4.8 \\
Non-hepatic neoplasia & 16 & 4.5 \\
Obesity & 15 & 4.2 \\
Autoimmunity & 5 & 1.4 \\
HBV co-infection & 3 & 0.8 \\
Anemia/thrombocytopenia & 3 & 0.8 \\
\hline
\end{tabular}

a $75 \%$ older than 70 years of age.

Comparison of the features of the subjects older than $\geq 65$ years of age according to treatment received is shown in Table 3. Untreated subjects were more likely older (mean age 73.4 years vs. 68.9 years; $p \leq 0.01$ ), with lower mean ALT values $(70 \mathrm{IU} / \mathrm{ml}$ vs. $102 \mathrm{IU} / \mathrm{ml} ; p \leq 0.01)$ and had a higher proportion of subjects with persistently normal alanine aminotransferase values ( $13.9 \%$ vs. 0 ).

The analysis of baseline characteristics of 37 subjects who refused antiviral therapy shows a preponderance of females (64.9\%), a very low proportion (8.6\%) of subjects with the highest educational level, and a prevalence of HCV genotype $1 \mathrm{a} / 1 \mathrm{~b}(65.4 \%)$ (Table 4).

We performed a multivariate analysis to identify variables independently associated with refusal of therapy. After adjusting for the confounding effect of all considered variables, we found that female gender (O.R. 2.27; 95\% C.I. 1.05-4.90), and, to a major extent, a lower education level (O.R. 4.48; 95\% C.I. 1.27-15.11), both were independent predictors of the likelihood of declining therapy. HCV genotype $1 \mathrm{a} / 1 \mathrm{~b}$ did not show an association (Table 5 ).

Table 3

Comparison of baseline features of anti-HCV positive patients older than 65 years of age according to antiviral therapy.

\begin{tabular}{|c|c|c|c|}
\hline Variable & Treated $(n=21)$ & Untreated $(n=218)$ & $p$ \\
\hline Age, years (mean \pm S.D.) & $68.9 \pm 2.6$ & $73.4 \pm 5.0$ & $<0.001$ \\
\hline \multicolumn{4}{|l|}{ Gender } \\
\hline Male & $13(61.9 \%)$ & $115(52.8 \%)$ & \multirow[t]{2}{*}{0.4} \\
\hline Female & $8(38.1 \%)$ & $103(47.2 \%)$ & \\
\hline B.M.I., $\mathrm{kg} / \mathrm{m}^{2}$ (mean \pm S.D.) & $25.9 \pm 3.1$ & $26.6 \pm 4.0$ & 0.4 \\
\hline ALT, IU/ml (mean \pm S.D.) & $102 \pm 53$ & $70 \pm 52$ & 0.008 \\
\hline \multicolumn{4}{|l|}{ Years of schooling ${ }^{\mathrm{a}}$} \\
\hline$<6$ & $10(52.6 \%)$ & $89(44.5 \%)$ & \multirow[t]{3}{*}{0.5} \\
\hline $6-12$ & $6(31.6 \%)$ & $89(44.5 \%)$ & \\
\hline$\geq 13$ & $3(15.8 \%)$ & $22(11.0 \%)$ & \\
\hline \multicolumn{4}{|l|}{ HCV genotype ${ }^{a}$} \\
\hline $1 a / 1 b$ & $13(68.4 \%)$ & $92(71.3 \%)$ & \multirow[t]{3}{*}{0.8} \\
\hline $2 a / 2 c$ & $6(31.6 \%)$ & $37(28.7 \%)$ & \\
\hline $3 a / 4$ & 0 & 0 & \\
\hline \multicolumn{4}{|l|}{ Diagnosis } \\
\hline PNALT carrier & 0 & $30(13.9 \%)$ & \multirow[t]{3}{*}{0.01} \\
\hline Chronic hepatitis & $20(95.2 \%)$ & $136(63.0 \%)$ & \\
\hline Cirrhosis & $1(4.8 \%)$ & $50(23.1 \%)$ & \\
\hline \multicolumn{4}{|l|}{ Referral pattern ${ }^{\mathrm{a}}$} \\
\hline Self-referral & $2(10.5 \%)$ & $18(8.5 \%)$ & \multirow[t]{3}{*}{0.3} \\
\hline General practitioner & $14(73.7 \%)$ & $123(58.0 \%)$ & \\
\hline Other & $3(15.8 \%)$ & $71(33.5 \%)$ & \\
\hline
\end{tabular}

a Some data are missing. PNALT: persistently normal alanine aminotransferase.
Table 4

Baseline features of 37 anti-HCV positive patients who refused antiviral therapy.

\begin{tabular}{ll}
\hline Variable & \\
\hline Age, years (mean \pm S.D.) (range) & $57.9 \pm 12.8(26-80)$ \\
Age class & \\
$\quad<40$ years & $4(10.8 \%)$ \\
$40-65$ years & $23(62.2 \%)$ \\
$>65$ years & $10(27.0 \%)$ \\
Gender & \\
Male & $13(35.1 \%)$ \\
Female & $24(64.9 \%)$ \\
B.M.I., kg/m ${ }^{2}($ mean \pm S.D.) & $26.5 \pm 2.4$ \\
ALT, IU/ml (mean \pm S.D.) & $87 \pm 101$ \\
Years of scholarship ${ }^{\mathrm{a}}$ & \\
$<6$ & $12(34.3 \%)$ \\
6-12 & $20(57.1 \%)$ \\
$\geq 13$ & $3(8.6 \%)$ \\
HCV genotype & \\
1a/1b & \\
2a/2c & $17(65.4 \%)$ \\
3a/4 & $7(26.9 \%)$ \\
Diagnosis & $2(7.7 \%)$ \\
PNALT carrier & \\
Chronic hepatitis & \\
Cirrhosis & $7(18.9 \%)$ \\
Referral pattern & $28(75.7 \%)$ \\
Self-referral & $2(5.4 \%)$ \\
General practitioner & \\
Other & $3(8.1 \%)$ \\
\hline & $22(59.5 \%)$ \\
Somed & $12(32.4 \%)$ \\
\hline
\end{tabular}

a Some data are missing. PNALT: persistently normal alanine aminotransferase.

\section{Discussion}

In this large multicenter prospective cohort study nearly two thirds of HCV-RNA positive subjects resulted not eligible for the current standard of antiviral therapy (i.e. PEG-IFN plus ribavirin). These findings from the real world are very different from those reported in international randomized clinical trials, where only $22.2-33.9 \%$ of screened patients resulted not eligible for PEG-IFN plus ribavirin therapy [6,7]. In contrast, the present findings are in agreement with previous reports performed in real world settings. A retrospective study of $293 \mathrm{HCV}$-infected patients attending a referral liver unit in Cleveland, Ohio, and a prospective multicenter study of 4084 veterans referred for $\mathrm{HCV}$ treatment over a one year period at 24 Veterans Affairs (VA) Medical Centers showed that only $28.3 \%$ and $32.2 \%$ patients, respectively, were considered eligible for antiviral treatment $[2,3]$. Only $8(9.5 \%)$ out of the 84 unselected HCV-RNA positive subjects detected by screening of the general population in a small Southern Italian town, seen in a single liver unit, received treatment [5].

A previous Italian study [4] has shown that the rate of eligibility to antiviral therapy was lower than we found in our survey (26\% vs. 33\%), but this divergence could be related to different treatment guidelines in 2004 with respect to current recommendations (possibility to treat patients over 65 years of age, and those with persistently normal alanine aminotransferase).

Overall, these data add more evidence of a lack of applicability of trial results in real world patients and the limited effectiveness of the current standard therapy for HCV infection, despite its good efficacy $[8,9]$.

In the USA ongoing substance abuse (alcohol and/or illicit drugs) is the strongest predictor (O.R. $=17.68$; 95\% C.I. 12.24-25.53) of not being a treatment candidate [3]. In our experience the majority (nearly half of cases) of untreated patients were older that 65 years of age, with $75 \%$ over 70 years and thus likely not suitable for treatment. This is a serious treatment barrier to overcome even 
Table 5

Variables associated with treatment refusal in anti-HCV positive patients. Crude and adjusted Odds Ratios (O.R.) derived by multiple logistic regression analysis.

\begin{tabular}{|c|c|c|c|c|c|}
\hline Variable & Untreated $(n=37)$ & Treated $(n=177)$ & Crude O.R. (95\% C.I.) & Adjusted O.R. (95\% C.I.) & $\mathrm{p}$ \\
\hline \multicolumn{6}{|c|}{ Age (years) } \\
\hline$\leq 50$ & $8(21.6 \%)$ & $77(43.5 \%)$ & 1 & 1 & \\
\hline$>50$ & $29(78.4 \%)$ & $100(56.5 \%)$ & $2.79(1.21-6.45)$ & $1.84(0.75-4.55)$ & 0.2 \\
\hline \multicolumn{6}{|l|}{ Gender } \\
\hline Male & $13(35.1 \%)$ & $101(57.1 \%)$ & 1 & 1 & \\
\hline Female & $24(64.9 \%)$ & $76(42.9 \%)$ & $2.46(1.18-5.15)$ & $2.27(1.05-4.90)$ & 0.036 \\
\hline \multicolumn{6}{|c|}{ Years of schooling ${ }^{\mathrm{a}}$} \\
\hline$\geq 13$ & $3(8.6 \%)$ & $48(30.4 \%)$ & 1 & 1 & \\
\hline$<13$ & $32(91.4 \%)$ & $110(69.6 \%)$ & $4.66(1.36-15.94)$ & $4.38(1.27-15.11)$ & 0.019 \\
\hline \multicolumn{6}{|c|}{ HCV genotype ${ }^{a}$} \\
\hline $2-3$ & $8(30.8 \%)$ & $55(34.2 \%)$ & 1 & & \\
\hline $1-4$ & $18(69.2 \%)$ & $106(65.8 \%)$ & $1.17(0.48-2.86)$ & & \\
\hline
\end{tabular}

a Some data are missing.

at a national level, because it reflects the epidemiological pattern of HCV infection common in all Italian areas as shown by several population-based surveys [10-13]. However, it should be considered that we are treating the patient and not the virus, in order to prevent HCV-related morbidity and mortality. Older patients with mild forms of chronic hepatitis and possibly with competitive causes of death are unlikely to have their life expectancy reduced by HCV infection. Therefore, although theoretically eligible, they do not require treatment, which could eradicate the virus but not change the expected natural history of their disease.

Decompensated cirrhosis represents a major contraindication to treatment, but patients with compensated cirrhosis, although less likely to respond, are susceptible to liver decompensation (preventable by $\mathrm{HCV}$ eradication) in their near future and strongly justify treatment.

Refusals represent a subgroup of untreated patients deserving special attention. A previous study has focused on the reasons for declining therapy, showing that concerns regarding potential side effects of therapies was one of the most important reason affecting therapy acceptance [3]. In this paper we evaluated the characteristics of the refusals: females and, to a major extent, subjects with low educational level were 2.3 -fold and 4.4-fold, respectively, more likely to decline treatment among subjects who were therapy candidates. Appropriate counselling should be addressed to these subjects in order to improve the rate of acceptance of antiviral treatment.

The strengths of the present survey comprise the inclusion of patients from several units (thus avoiding the single centre effect) and the prospective study design. However, the present study may have overestimated the proportion of subjects who are eligible fro treatment because of referral bias. In fact, the evaluation concerned subjects referred for HCV therapy and general practitioners may have only referred those that they perceived as good candidates.
In conclusion, these findings confirm previous reports that only a small proportion of candidates for HCV treatment results suitable for therapy. Despite the good efficacy of current HCV therapy, its effectiveness needs to be improved.

\section{References}

[1] Zeuzem S, Berg T, Moeller B, et al. Expert opinion on the treatment of patients with chronic hepatitis C. J Viral Hepat 2009;16:75-90.

[2] Falck-Ytter Y, Kale H, Mullen KD, et al. Surprisingly small effect of antiviral treatment in patients with hepatitis C. Ann Intern Med 2002;136:288-92.

[3] Bini EJ, Bräu N, Currie S, et al. Prospective multicenter study of eligibility for antiviral therapy among 4,084 U.S. veterans with chronic hepatitis C virus infection. Am J Gastroenterol 2005;100:1772-9.

[4] Framarin L, Tappero G, Ayoubi M, et al. Eligibility for therapy among chronic HCV-infected patients in a primary referral center. Dig Liver Dis 2004;36:A30.

[5] Mariano A, Caserta C, Pendino GM, et al. Antiviral treatment for hepatitis C virus infection: effectiveness at general population level in a highly endemic area. Dig Liver Dis 2009;41:509-15.

[6] Manns MP, McHutchison JG, Gordon SC, et al. Peginterferon alfa-2b plus ribavirin compared with interferon alfa-2b plus ribavirin for initial treatment of chronic hepatitis C: a randomised trial. Lancet 2001;358:958-65.

[7] Fried MW, Shiffman ML, Reddy KR, et al. Peginterferon alfa-2a plus ribavirin for chronic hepatitis C virus infection. N Engl J Med 2002;347:975-82.

[8] Rizzetto M, Colombo M, Ascione A, et al. Effectiveness of epatiti C virus treatment in real-life practice: a prospective observational multi center study in Italy (PROBE). J Hepatol 2008;48(Suppl. 2):S311.

[9] Rosina F, Tosti ME, Borghesio E, et al. PEG-IFN for Hepatitis C in clinical practice. Dig Liver Dis 2009;41(Suppl. 1):S52.

[10] Stroffolini T, Menchinelli M, Taliani G, et al. High prevalence of hepatitis C virus infection in a small central Italian town: lack of evidence of parenteral exposure. Ital J Gastroenterol 1995;27:235-8.

[11] Guadagnino V, Stroffolini T, Rapicetta M, et al. Prevalence, risk factors, and genotype distribution of hepatitis $C$ virus infection in the general population: a community-based survey in southern Italy. Hepatology 1997;26:1006-11.

[12] Maio G, d'Argenio P, Stroffolini T, et al. Hepatitis C virus infection and alanine transaminase levels in the general population: a survey in a southern Italian town. J Hepatol 2000;33:116-20.

[13] Di Stefano R, Stroffolini T, Ferraro D, et al. Endemic hepatitis C virus infection in a Sicilian town: further evidence for iatrogenic transmission. J Med Virol 2002;67:339-44. 